\title{
Relationship between the carotenoid content, dry matter content and sensory attributes of sweet potato
}

\author{
Keith Tomlins ${ }^{a,{ }^{*}}$, Constance Owori ${ }^{b}$, Aurelie Bechoff ${ }^{a}$, Geoffrey Menya ${ }^{b}$ and Andrew \\ Westby $^{\mathrm{a}}$ \\ a Natural Resources Institute, University of Greenwich, Central Avenue, Chatham Maritime, \\ Kent, ME7 3RU, United Kingdom \\ b National Agricultural Research Laboratories, P. O BOX 7065, Kampala, Uganda
}

Correspondence to: Keith Tomlins, E-mail: K.I.Tomlins@gre.ac.uk; Fax +44 1634883567

\begin{abstract}
The sensory characteristics of biofortified sweet potato in Africa were explored over a wide range of carotenoid ( 0.4 to $72.5 \mu \mathrm{g} / \mathrm{g}$ fresh weight) and dry matter contents (26.8 to $39.4 \%$ ). The logarithm of the total carotenoid content was correlated with the dry matter content (declining by $1.2 \%$ with each doubling of the carotenoid content) and a wide range of sensory characteristics that involve visual, odour, taste and textural characteristics. Multiple linear regression models were developed. The logarithmic relationship of colour with the carotenoid concentration means that those varieties with a relatively low carotenoid content may appear to
\end{abstract}


be of similar intensity to ones which a much higher and hence nutritionally beneficial carotenoid content.

Keywords: sensory evaluation, sweet potato, ipomoea batatas, carotenoid, dry matter, logarithm

\section{Introduction}

Sweet potato (Ipomoea batatas (L) Lam) is among the most under-exploited of the developing world's major crops (Walker and Crissman 1996). Traditionally, sweet potato varieties produced and sold in Southern Africa have a pale coloured flesh, but new biofortified orange flesh sweet potato varieties (OFSP) have been introduced that contain high concentrations of $\beta$-carotene (pro-vitamin A). Vitamin A deficiency is a leading cause of early childhood death and a major risk factor for pregnant and lactating women; it is estimated that worldwide, tens of thousands of deaths occur annually among young children (McGuire 1993). Impact assessment studies (Low et al., 2001, Low et al., 2007) have indicated that OFSP can make a major contribution to alleviating vitamin A deficiency in Sub-Saharan Africa and indicated that the daily addition of orange-fleshed sweet potato to the diet could prevent vitamin A deficiencies in children, pregnant women, and lactating mothers. An efficacy study (Jaarsveld et al., 2005) in South Africa had demonstrated that consumption of 125g OFSP improved the vitamin A status of children and can play a significant role in developing countries as a viable long-term food-based strategy for controlling vitamin A deficiency. A review of the importance of sweet potato as an intervention food to prevent vitamin A deficiency has recently been published by Burri 2011. Replacing the pale-fleshed varieties now grown by farmers with new high $ß$-carotene varieties 
could benefit an estimated 50 million children under age 6 who are currently at risk. For example, the majority of children in Burundi, Rwanda and Uganda would benefit, as would about half of the children in Tanzania and to a lesser degree those in Ethiopia, Kenya and South Africa (Walker and Crissman 1996).

Changes in appearance, taste and texture may be a barrier to consumer acceptance of fresh OFSP, particularly when it is a primary staple. Orange fleshed sweet potato contains carotenoids (O`Connell et al., 2007; Maoka et al., 2007 and Bengsston et al., 2008). In Africa, consumers have been reported to prefer high dry matter varieties of sweet potato (Operia \& Sun 1988, Kapinga \& Cary 2003), and varieties of sweet potato with high carotenoid contents tend to have lower dry matter contents. International Potato Center (CIP) has been breeding specifically for varieties of OFSP that are high in both carotenoid and dry matter content.

The sensory characteristics of OFSP and non-orange varieties have been reported (Tomlins et al., 2007: Ofori et al., 2009, Leighton et al., 2010). Orange fleshed varieties are associated with sensory attributes such as pumpkin flavour, watery texture and orange colour while yellow and white varieties were associated with the descriptive terms creamy colour, starchiness, hard texture, coarse texture, yellow colour, fibrous texture and sweet taste (Tomlins et al., 2007). Leighton et al., 2010 reported that OFSP differed in color, was sweeter and displayed flavour characteristics of yellow vegetables (such as butternut and pumpkin) when compared with white fleshed varieties. Ofori et al., 2009 relied on using acceptance criteria and did not use the sensory panel to describe the sensory attributes of OFSP or how it differed from white varieties. Little, however, appears to have been reported that explore the relationship between the sensory characteristics and the physical and chemical constituents such as carotenoids or dry matter. For example, for consumers in Africa, it has been reported that they 
prefer high dry matter varieties of sweet potato (Operia \& Sun 1988, Kapinga \& Cary 2003). OFSP varieties of sweet potato with high carotenoid contents not only differ in colour but also tend to have lower dry matter contents.

Therefore, it would be of interest to explore how the sensory properties of sweet potato might vary with the carotenoid and dry matter content.

In this study, the sensory characteristics of 11 sweet potato cultivars with varying carotenoid and dry matter contents in Uganda were compared.

\section{Materials and Methods}

\subsection{Sweet potato samples}

Eleven sweet potato varieties were tested. These were orange fleshed (Ejumula, Kakamega, SPK004/1, SPK004/6/6 and SPK004/1/1), yellow fleshed (Tanzania and Naspot 1) and white fleshed (Dimbuka, Nakakande, New Kawogo and Ndikirya N'omwami).

\subsection{Cooking of sweet potato samples}

Roots (fresh) were sorted to remove diseased and insect damaged ones and boiled until the texture, assessed by a fork, was considered correct for eating. Preliminary trials indicated that this method was consistent and allowed for slight differences in cooking times with variety.

\subsection{Ethical assessment and consent}


This research has been assessed and approved by the University of Greenwich Research Ethics Committee. Written consent was sought from panellists participating in this study and they were informed that their participation was entirely voluntary and that they could withdraw from the panel at any time.

\subsection{Sensory evaluation}

Cooked sweet potato samples were scored by a semi-trained sensory panel using a modified version of quantitative descriptive analysis (QDA) since standards were not provided (Meilgaard et al., 2007). The sensory panel which comprised ten panellists was conducted at the National Agricultural Research Laboratory, Uganda under ambient temperature and controlled lighting. The language used for the sensory testing was English. The panellists had been screened for familiarity with the product. Sensory attributes were generated during a preliminary focus group session guided by the panel leader. A total of 13 sensory attributes were developed for the cooked sweet potato for which the group of panellists had a consensus. Sensory attributes generated were as follows:

- Sweet potato odour - odour characteristic of sweet potato

- Pumpkin odour - odour characteristic of pumpkins

- Smooth appearance - sweet potato that have an even surface

- Yellow colour - flesh that is yellow in colour

- Orange colour - flesh that is orange in colour

- White colour - flesh that is white in colour 
- Uniform colour - sweet potato that is even in colour and with minimal variation

- Sweet taste - tastes like sugar

- Pumpkin taste - taste that is characteristic of pumpkin

- Crumbly texture (in the hand) - sweet potato is brittle and flaky when compressed by the fingers

- $\quad$ Soft texture - texture that is squashy and yielding

- Fibrous texture - the quality of being fibrous

- Watery texture - texture that is moist

After a period of training using these attributes, the eleven sweet potato samples were tested blind in duplicate by the panel and the order in which they were presented was random. At each session, four sweet potato samples (coded with 3-figure random numbers) were served on white paper plates in random order to each panellist. Cooked sweet potato samples (40 g) were tested by the panellists at ambient temperature $\left(25^{\circ} \mathrm{C}\right.$ to $\left.30^{\circ} \mathrm{C}\right)$. Intensity for the sensory attributes was scored on a $100 \mathrm{~mm}$ unstructured scale, anchored with the terms 'not very' at the low end and 'very' at the high end.

\subsection{Total carotenoid and dry matter content analysis of sweet potato}

Total carotenoid content and dry matter was determined on the fresh roots. A total of five roots were randomly selected for each variety for analysis which were quartered and pureed. Total carotenoid extraction and analysis was carried out in triplicate following an existing method (Rodriquez and Kimura 2004; Bechoff et al., 2010). 1-6 g fresh tissue (the amount collected 
depended on an estimate of the level of total carotenoid in the sweet potato) was homogenised with 50ml methanol-tetrahydrofuran (THF) (1 : 1) using a Polytron PT1200E (Kinematica, Lucerne, Switzerland) homogeniser or an Ultra-turax (IKA Janke and Kunkel Labortechnik, Germany) for $1 \mathrm{~min}$. The carotenoid content was measured using a UV-visible spectrophotometer (Genesys 10UV, VWR, UK) at a wavelength of $450 \mathrm{~nm}$. Concentrations were determined by comparison to an external standard curve using pure $\beta$-carotene (Sigma-Aldrich, Gillingham, UK) and an absorption coefficient of $\beta$-carotene in PE of 2592.14. Total carotenoid determination has been reported to be an acceptable technique to give a close estimate of trans- $\beta$ carotene content in OFSP since $90 \%$ of the total carotenoid content of sweet potato is $\beta$-carotene (Rodriguez \& Kimura 2004; Bengtsson et al., 2008).

Dry matter determinations were assessed by drying triplicate $5 \mathrm{~g}$ samples (AOAC 1994).

\subsection{Statistical Analysis}

Analysis of variance, correlation analysis (Pearson), stepwise multiple linear regression and principal component analysis (correlation matrix) were carried out using SPSS (V 16.0) or XLSTAT (V 5.2, Addinsoft). A mixed effect model for each of the sensory qualities was undertaken with R (lme4 package). Multiple pairwise comparisons were undertaken using the tukey test with a confidence interval of $95 \%$.

\section{Results and Discussion}


3.1. Relationship between the sensory attributes and varieties of sweet potato with varying total carotenoid and dry matter contents

The sensory attributes of the 11 sweet potato cultivars tested were strongly significantly different with respect to variety (linear mixed model; ANOVA; $\mathrm{P}<0.001$ ) for all of the sensory attributes (sweet potato odour, pumpkin odour, smooth appearance, yellow colour, orange colour, white colour, uniform colour, sweet taste, pumpkin taste, crumbly texture, soft texture and watery texture) apart from fibrous which was only significant at $\mathrm{P}<0.05$. Table 1 shows the mean values for each variety and sensory attribute. The tukey test indicates that for each sensory attribute, the 11 cultivars were generally significantly different as a minimum of three groups and up to six. The least overlap between varieties was for the sensory attributes based on appearance.

To test whether the variability in the sensory results might be due to panellists using different parts of the scale, a mixed effect model was fitted with the panellists and panellists and variety interactions as random effects. The probability values are shown in Table 2 and suggest that for the majority of the sensory attributes the scaling issue was not a significant factor while it was for pumpkin odour, and pumpkin taste. It is speculated that the reason why there were differences for the 'pumpkin' sensory attribute is because some of the Ugandan sensory panellists may not have been familiar with eating it.

Principal component analysis (PCA) was used to summarize the relationships between the sensory attributes and the sweet potato samples (Fig. 1). The PCA plot, accounting for $89 \%$ of the total variation, illustrates that the orange (Ejumula, SPK004/1, SPK004/6/6, Kakamega and 
SPK004/1/1), yellow (Tanzania and Naspot 1) and white (Dimbuka, Nakakande, New Kawogo and Ndikirya N'omwami) cultivars widely differed with respect to their sensory characteristics. The orange cultivars were associated with pumpkin odour and taste, orange and uniform colour, soft and watery texture and smooth appearance, while the yellow varieties were associated with yellow colour and white fleshed varieties with sweet taste, crumbly texture, sweet potato odour and white colour. The fact that the OFSP varieties were associated with a watery texture also suggests that they have a lower dry matter content and therefore a possible correlation.

The differences in sensory attributes between orange and non-orange cultivars is similar to those previously reported for varieties in Tanzania (Tomlins et al. 2007) where high carotene varieties were associated with water texture, pumpkin flavour and orange colour while low carotenoid varieties were described as having the characteristics of sweet tasting, yellow colour, creamy colour, starchiness, hard texture, coarse texture and fibrous texture. Similarly, Leighton et al., 2010 reported that OFSP differed in colour, was sweeter and displayed flavour characteristics of yellow vegetables (such as butternut and pumpkin) when compared with white fleshed varieties.

\subsection{Relationship between the total carotenoid and dry matter contents}

The relationship between sensory attributes and dry matter was explored because consumers in Africa have been reported to prefer high dry matter varieties of sweet potato (Operia \& Sun 1988, Kapinga \& Cary 2003), and a challenge was that varieties of biofortified sweet potato with high carotenoid contents tend to have lower dry matter contents. 
The major carotenoid of OFSP is all-trans b-carotene but $\alpha$-carotene and including the alltrans and cis forms are also present s (O`Connell et al., 2007; Maoka et al., 2007: Bengsston et al., 2008 and Liu et al., 2009). However, for the purposes of this investigation, the total carotenoid determination has previously been reported to be an acceptable method to give a good estimate of all trans $\beta$-carotene since $90 \%$ of the total carotenoid content is $\beta$-carotene (Bechoff et al., 2010).

The total carotenoid ( $\mu \mathrm{g} / \mathrm{g}$ fresh weight) and dry matter $(\%)$ contents of the 11 varieties of sweet potato varying from deep orange in colour to white are given in Table 3 . The carotenoid content of the sweet potato was expressed on a fresh weight when exploring the relationships because the product is traded and consumed in the fresh form. However, it is also, expressed on a dry weight basis (table 3) so that the results can be compared with other publications that have expressed the content on a dry weight basis. The results show a wide variation in carotenoid content from 0.4 to $72.5 \mu \mathrm{g} / \mathrm{g}$ fresh weight and dry matter content from 26.8 to $39.4 \%$.

A comparison of the carotenoid content and dry matter contents measured in this study with those reported elsewhere (Namutebi et al., 2004, Bengsston et al., 2008 and Bechoff et al., 2010) (table 4) indicated that the values were within the range previously found.

In general, the dry matter content of the sweet potato declined with increasing carotenoid content. While there was no significant linear relationship between the dry matter and total carotenoid content, there was a significant correlation with the logarithm of the carotenoid content $(\mathrm{P}<0.05 ; \mathrm{R}=-0.747)$. The curve is illustrated in Fig. 2 and shows that the dry matter declines with increasing carotenoid content, at first rapidly and then more slowly. While there is no theoretical reason for fitting a logarithmic curve it gave a significant fit and in particular, fitted the initial steep decline in dry matter content at low carotenoid levels (less than $5 \mu \mathrm{g} / \mathrm{g}$ fresh 
weight). A feature of logarithmic curves is that there is a common geometric ratio linking the dry matter content and carotenoid content. For example, for these sweet potato samples, each time the carotenoid content of sweet potato doubles, the dry matter decreases by about $1.2 \%$.

The fairly wide scatter about the mean dry matter content value of $\pm 4 \%$ suggests that other factors such as the selection of high carotenoid varieties with higher dry matter contents, environmental (weather, soil, farming practices) and maturity might be important.

Hagenimara et al 1999 reported that there was very little relation between the flesh colour and the dry matter content of sweet potato roots apart from dry matter contents being low to medium for orange fleshed roots and generally higher for white flesh roots. A genetic correlation $\left(r_{g}=0.6\right.$ to 0.8$)$ between high $\beta$-carotene accumulation and low dry matter (low starch) content has been reported although it is not clear whether they are based on functional links between starch and carotenoid accumulations. Within breeding programmes combining high $\beta$-carotene and high dry matter is difficult but successful, so that the genetic correlation might be due to genepool separation (Gruneberg, W. Pers. Comm.). This appears to be the first time that such a curve has been has been suggested for the relationship between dry matter content and the carotenoid content of sweet potato.

\subsection{Correlations of the sensory attributes with dry matter and total carotenoids (expressed on a fresh weight basis)}

Correlations between the sensory scores for each attribute and with the dry matter content and logarithm of the carotenoid content (base on fresh weight) are shown in Table 5. The correlations were based on 11 cultivars. The carotenoid content was expressed on a fresh weight 
basis because the sensory panellists assessed the product in as a wet product. Logarithmic curves were fitted because these were generally highly significant and followed the same pattern as for the relationship between dry matter and the carotenoids (Fig 2). The correlations were significant for all of the sensory attributes apart from the yellow colour and uniform colour. Therefore, varying the carotenoid content of led to variations in a wide spectrum of sensory attributes spanning the appearance, odour, taste and texture.

Since the total carotenoid content and dry matter content were correlated, stepwise multiple linear regressions were used to develop models that related them to the sensory attributes.

The regression models indicated that sweet potato odour, pumpkin odour, smooth appearance, orange colour, white colour and pumpkin taste were correlated with the logarithm of the carotenoid content (Fig. 3). The models for the sensory attributes sweet taste, crumbly texture (hand) and watery texture were correlated with the dry matter content (Fig 4).

Variations of the carotenoid content of sweet potato is clearly linked with changes in the dry matter content and a wide range of sensory attributes that relate to the entire sensory spectrum relating to odour, appearance, taste and texture. It is speculated that in plants, carotenoids not only influence the light absorption properties, and hence colour, but have a wider role (Britton 1995). Their chemical and physical properties are strongly influenced by other molecules in their vicinity, especially proteins and membrane lipids (Britton 1995). In sweet potato, a genetic correlation $\left(r_{g}=0.6\right.$ to 0.8$)$ between high $\beta$-carotene accumulation and low dry matter (low starch) content suggests relationships with textural changes (Gruneberg, W. Pers. Comm.). In other commodities such a as carrots (Berger et al., 2008), variations in carotenoid 
content were significantly correlated to texture attributes (fibrous and tender textures). Carrots with high carotene content were more solid and less tender. For tomato and watermelon, carotenoid pigmentation patterns had profound effects on the norisoprene and monoterpene aroma volatile compositions (Lewinsohn et al., 2005). This perhaps may contribute to explaining why carotenoids were associated with the odour of sweet potato in this study.

Of the sensory attributes that related to the carotenoid contents, the most visible to consumers is the colour (orange) and this clearly identifiable visible trait can influence marketing and promotion (Tomlins et al., 2010). A particular feature of the colour is that the most intense orange coloured varieties will contain the greatest concentration of carotenoids (pro-vitamin A) and hence potential nutritional benefit to consumers, in particular children (van Jaarsveld et al., 2005; Low et al., 2007). However, since the visual orange colour appears to have a logarithmic relationship with the carotenoid concentration, those OFSP varieties with a relatively low carotenoid content may appear to be of similar intensity to ones which a much higher and hence nutritionally beneficial carotenoid content. Thus consumers who select sweet potato for its potential nutritional benefit based on its orange colour alone may select ones that are not as beneficial as they are perceived to be.

In addition, the impact of variations in total carotenoids on a wide spectrum of sensory attributes (odour, appearance, taste and texture) may have an effect on consumer acceptance. For example, in consumer acceptance studies involving 94 school children and 59 mothers with preschool children in the Lake Zone of Tanzania reported three different categories of consumer acceptance for sweet potato of differing carotenoid content (Tomlins et al., 2007).

\section{Conclusion}


The sensory characteristics of sweet potato in Africa have been investigated over a wide range of carotenoid ( 0.4 to $72.5 \mu \mathrm{g} / \mathrm{g}$ fresh weight) and dry matter contents ( 26.8 to $39.4 \%$ ). It is suggested that the logarithm of the total carotenoid content is significantly (often highly) correlated with the dry matter content and a wide range of sensory characteristics that involve visual, odour, taste and textural characteristics. This also implies that the carotenoids have a complex effect on the sweet potato storage root.

Multiple linear regression models indicated that carotenoids and dry matter were related to different sensory aspects of sweet potato. Sweet potato odour, pumpkin odour, smooth appearance, orange colour, white colour and pumpkin taste were correlated with the logarithm of the carotenoid content. The models for the sensory attributes sweet taste, crumbly texture (hand) and watery texture were correlated with the dry matter content. The effect of varying the carotenoids over a wide spectrum of sensory attributes may have implications for consumer acceptance of varieties that contain high levels of carotenoids.

Of the sensory attributes that related to the carotenoid contents, the most visible to consumers is the orange colour and this clearly identifiable visible trait can influence marketing and promotion (Tomlins et al., 2010). The suggested logarithmic relationship of colour with the carotenoid concentration means that those OFSP varieties with a relatively low carotenoid content may appear to be of similar intensity to ones which a much higher and hence nutritionally beneficial carotenoid content. Thus consumers who select sweet potato for its potential nutritional benefit based on its orange colour alone may select ones that are not as beneficial as they are perceived to be. 
Regarding the dry matter content, in this research, each doubling of the carotenoid content would result in a decrease of about $1.2 \%$. However, the wide variability about the regression suggests that other factors also contribute to the variability.

It would be interest to explore the relationship between the carotenoid content and the sensory and physic-chemical attributes of other root crops such as cassava that contain carotenoids and potentially non-root crops such as rice and maize.

Finally, the proposed logarithmic curve correlation is based on empirical evidence. A model to explain the nature of the variation needs to be identified.

\section{Acknowledgements}

This publication is dedicated to one of the co-authors, Constance Owori, who sadly died shortly after the fieldwork was completed. She made a significant contribution to this research. This publication is an output from a research project funded by the Bill and Melinda Gates Foundation (Product development and marketing component of REU of HarvestPlus Challenge Program). The views expressed are not necessarily those of the HarvestPlus Research Programme or the Bill and Melinda Gates Foundation

\section{References}

AOAC (1984) Official Methods of Analysis of the Association of Official Analytical Chemists. The Association of Official Analytical Chemists, Inc., Arlington, VA 
Bengtsson, A., Namutebi, A., Larsson Alminger, M., \& Svanberg, U. (2008) Effects of various traditional processing methods on the all-trans- $\beta$-carotene content of orange-fleshed sweetpotato. J Food Compos Anal, 21, 134-143.

Berger, M., Kuchler, T., Maaßen, A., Busch-Stockfisch, M., \& Steinhart, H. (2008) Correlations of carotene with sensory attributes in carrots under different storage conditions, Food Chemistry, 106, 235-240

Britton, G. (1995) Structure and properties of carotenoids in relation to function, The FASEB Journal, 9, 1551-1558

B.J.Burri (2011) Evaluating Sweet Potato as an Intervention Food to Prevent Vitamin A Deficiency. Comprehensive Reviews in Food Science and Food Safety, 10, 118-130.

Hagenimana, V., Carey, E.E., Gichuki, S.T., Oyunga, M.A., \& Imungi, J.K. (1998). Carotenoid contents in fresh, dried and processed sweetpotato products. Ecol. Food Nutr, 37, $455-473$

Jones, A., C.E. Steinbauer and D.T. Pope (1969). Quantitative inheritance of ten root traits in sweet potatoes. J. Am. Soc-Hortic. Sci. 94, 271-275.

Kapinga, R. E., \& Carey. E. E. (2003) Present status of sweetpotato breeding for eastern and southern Africa, In. Sweetpotato post-harvest assessment: experiences from East Africa, Eds. Rees, D., Oirschot, Q. \& Kapinga, R. Natural Resources Institute, Chatham, UK (ISBN 085954 5482), 3-8.

Leighton, C.S., Schönfeldt, H. C., \& Kruger, R. (2010) Quantitative descriptive sensory analysis of five different cultivars of sweet potato to determine sensory and textural profiles, Journal of Sensory Studies, 25, 2-18 
Lewinsohn, E., Sitrit, Y., Bar, E., Azulay, Y., Meir, A., Zamir, D., \& Tadmor, Y. (2005) Carotenoid pigmentation affects the volatile composition of tomato and watermelon fruits, as revealed by comparative genetic analyses. J Agric Food Chem, 53, 3142-8.

Low., J. Walker, T., \& Hijmans, R. (2001). The potential impact of orange-fleshed sweet potato on Vitamin-A intake in sub-Saharan Africa. Regional Workshop on Food Based Approaches to Human Nutritional Deficiencies: The VITAA Project, Vitamin A and Orangefleshed sweet potato in sub-Saharan Africa. May 9-11, 2001. Nairobi, Kenya.

Low, J. W., Arimond, M., Osman, N., Cunguara, B., Zano, P., \& Tschirley. T. (2007). A Food-Based Approach Introducing Orange-Fleshed Sweet Potatoes Increased Vitamin A Intake and Serum Retinol Concentrations in Young Children in Rural Mozambique, Journal of Nutrition, 137, 1320-1327

Liu, S., Lin, J., \& Yang D. (2009) Determination of cis- and trans- a- and b-carotenoids in Taiwanese sweet potatoes (Ipomoea batatas (L.) Lam.) harvested at various times, Food Chemistry, 116, 605-610

Maoka, T., Akimoto, N., Ishiguro, K., Yoshinaga, M., \& Yoshimoto, M. (2007) Carotenoids with a 5,6-dihydro-5,6-dihydroxy-b-end group, from yellow sweet potato “'Benimasari', Ipomoea batatas LAM, Phytochemistry, 68 1740-1745

McGuire, J. (1993). Addressing micronutrient malnutrition, Standing Committee on Nutrition News, 9, 1-10.

Meilgaard, M., Civile, G. V., \& Carr, B. T. (2007). Sensory Evaluation Techniques 4th Edition, CRC Press, Florida, USA.

Namutebi, A., Natabirwa, H., Lemaga, B., Kapinga, R., Matovu, M., Tumwegamire, S., Nsumba, J., and Ocom, J. (2004). Long-term storage of sweet potato by small-scale farmers 
through improved post harvest technologies. Uganda Journal of Agricultural Science, 9, 922930.

O’Connell, O. F., Ryan, L., O’Brien., \& N. M. (2007) Xanthophyll carotenoids are more bioaccessible from fruits than dark green vegetables, Nutrition Research, 27, 258-264

Ofori, G., Oduro, I., Ellis, W., \& Dapaah, K. (2009) Assessment of vitamin A content and sensory attributes of new sweet potato (Ipomoea batatas) genotypes in Ghana, African Journal of Food Science, 3, 184-192

Operia, R., \& Sun, P. (1988) AVRDC Sweet Potato Research Program, In Improvement of Sweet Potatoes in East Africa: With Some References of Other Tuber and Root Crops: Report, International Potato Centre

Rodriguez Amaya, D. B., \& Kimura, M. (2004) HarvestPlus Handbook for Carotenoid Analysis. [Online]. Available: http://www.harvestplus.org/content/harvestplushandbookcarotenoid-analysis [accessed 2 June 2010].

Tomlins, K., Ndunguru, G., Stambul, K., Joshua, N., Ngendello, T., Rwiza, E., Amour, R., Ramadhani, B., Kapande, A., \& Westby. A. (2007). Sensory evaluation and consumer acceptability of pale-fleshed and orange-fleshed sweetpotato by school children and mothers with preschool children, Journal of the Science of Food and Agriculture, 87, 2436-2446.

Tomlins, K., Rees, D., Coote, C., Bechoff, A., Okwadi, J., Massingue, J., \& Westby, A. (2010). Sweet potato utilization, storage, small-scale processing and marketing in Africa, In Sweet Potato: Post Harvest Aspects in Food, Feed and Industry, Eds Ray, R. \& Tomlins, K. (2010), Nova Science Publishers, Inc. New York, USA ISBN978-1-60876-343-6.

van Jaarsveld, P. J., Faber, M., Tanumihardjo, S. A., Nestel, P., Lombard, C. J., \& Spinnler Benadé, A. J. (2005). ß-Carotene-rich orange-fleshed sweet potato improves the vitamin 
A status of primary school children assessed with the modified-relative-dose-response test, American Journal of Clinical Nutrition, 81, 1080-1087.

Walker, T. S., \& Crissman, C. C. (1996). Case studies of the economic impact of CIP related technologies, International Potato Center, Lima, Peru, ISBN 92-9060-181-7. 


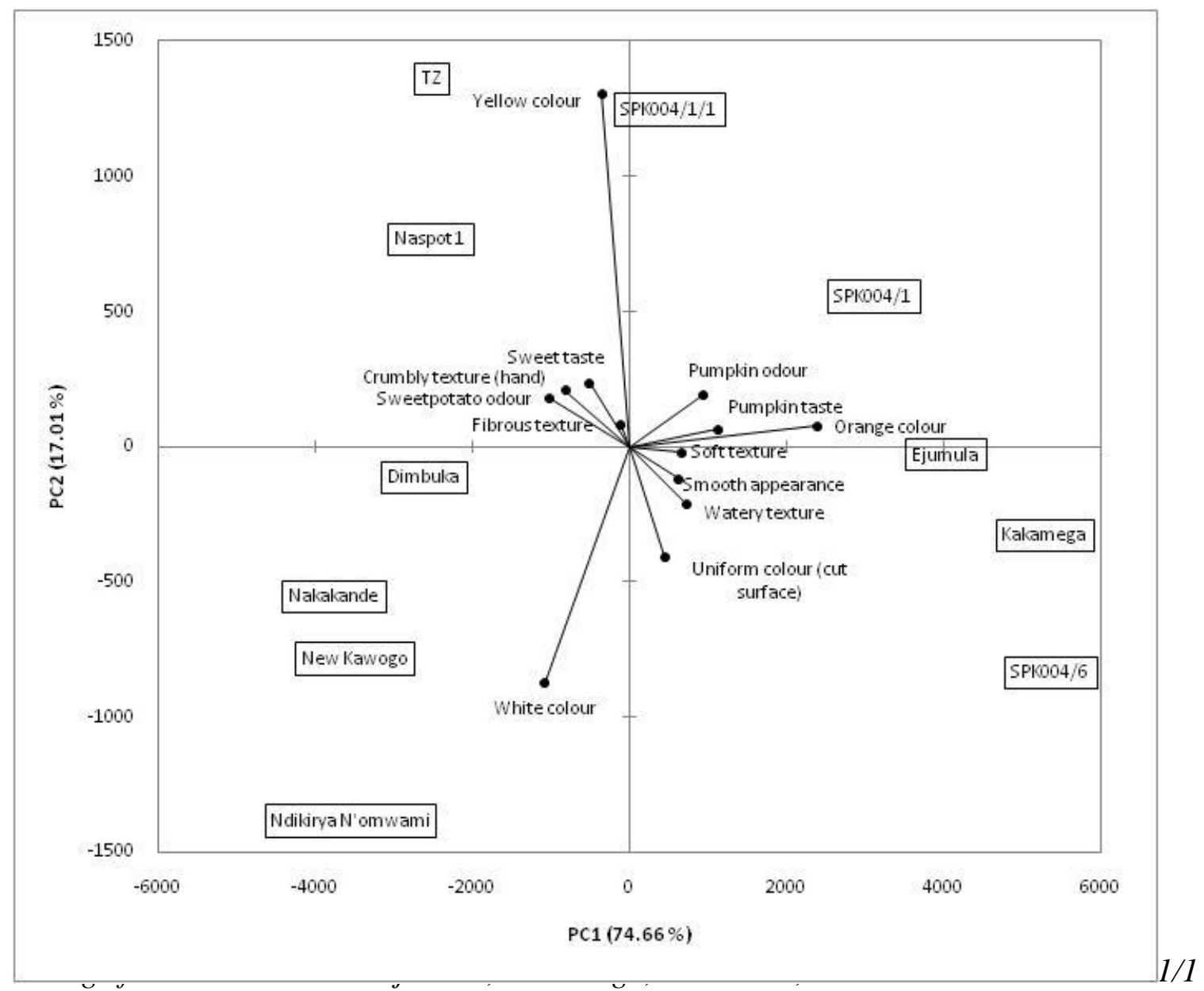

Yellow fleshed varieties $=$ Tanzania and Naspot 1

White fleshed varieties = Dimbuka, Nakakande, New Kawogo and Ndikirya N'omwami.

Fig. 1. Principal component plot illustrating the relationship between the sensory descriptors and sweet potato varieties tested 


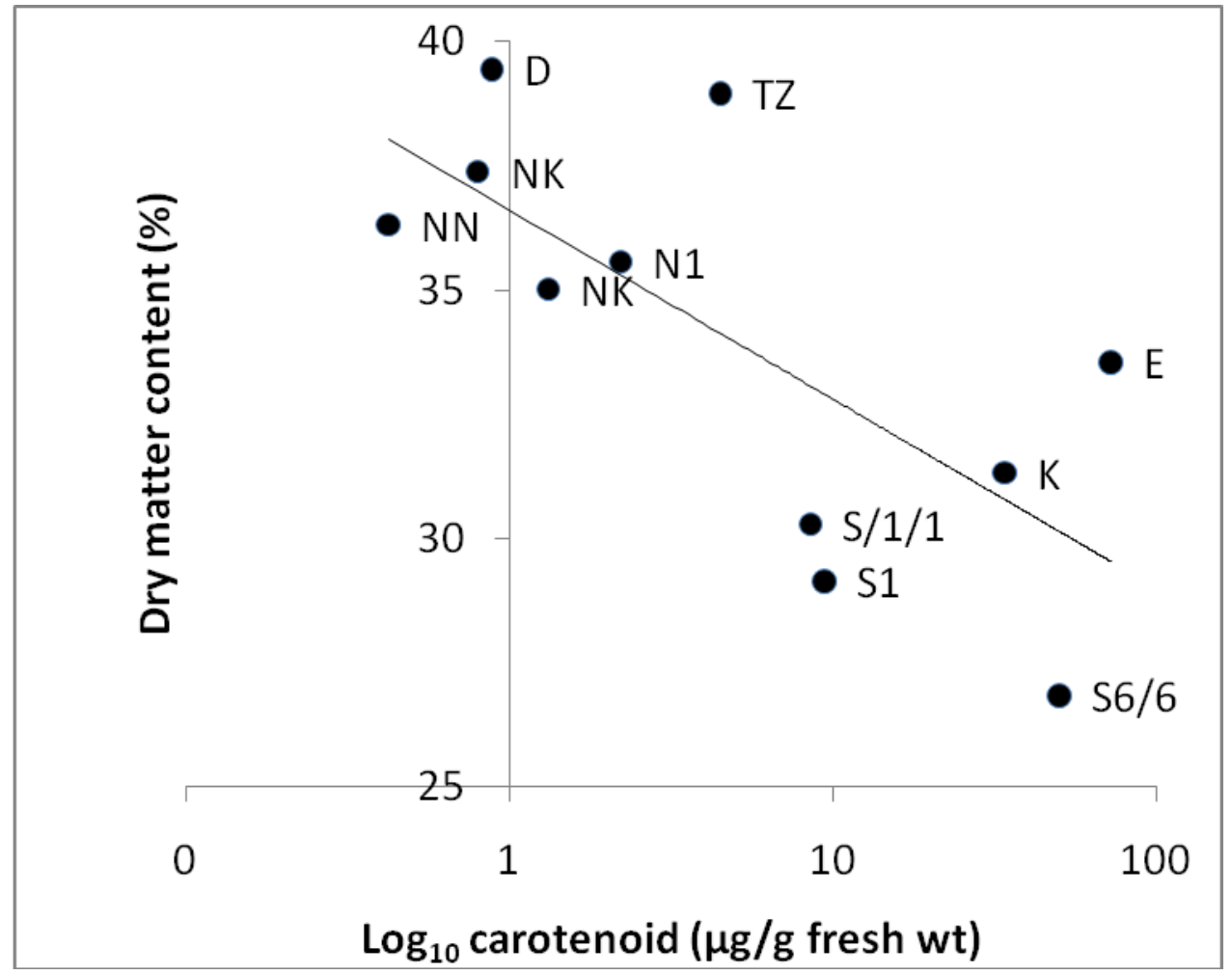

Where: $\mathrm{NN}=$ Ndikirya N'omwami, $\mathrm{NK}=$ Nakakande, $\mathrm{D}=$ Dimbuka, $\mathrm{NK}=$ New Kawogo, $\mathrm{N} 1=$ Naspot 1, TZ = Tanzania, S/1/1 = SPK004/1/1, S1 = SPK004/1, K = Kakamega, S6/6 = SPK004/6/6 and $\mathrm{E}=$ Ejumula

Fig 2. Relationship between dry matter $(\%)$ and logarithm of the total carotenoid content 


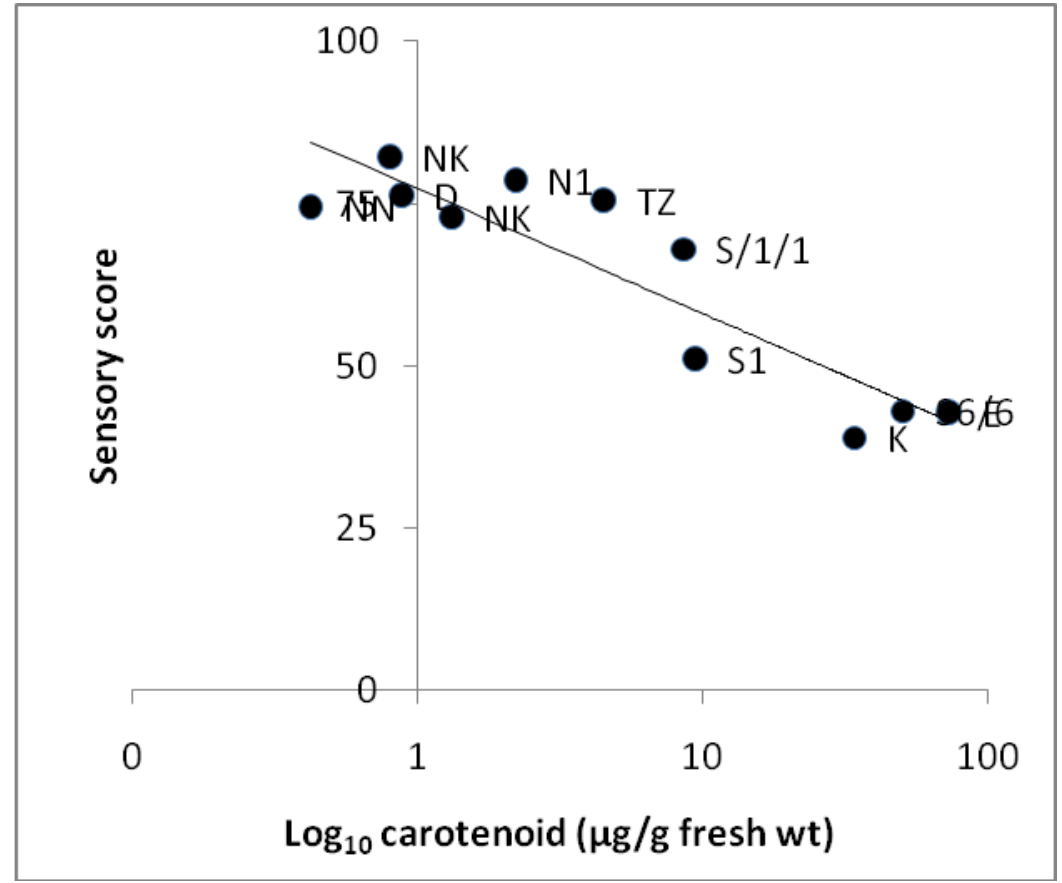

a) Sweet potato odour 


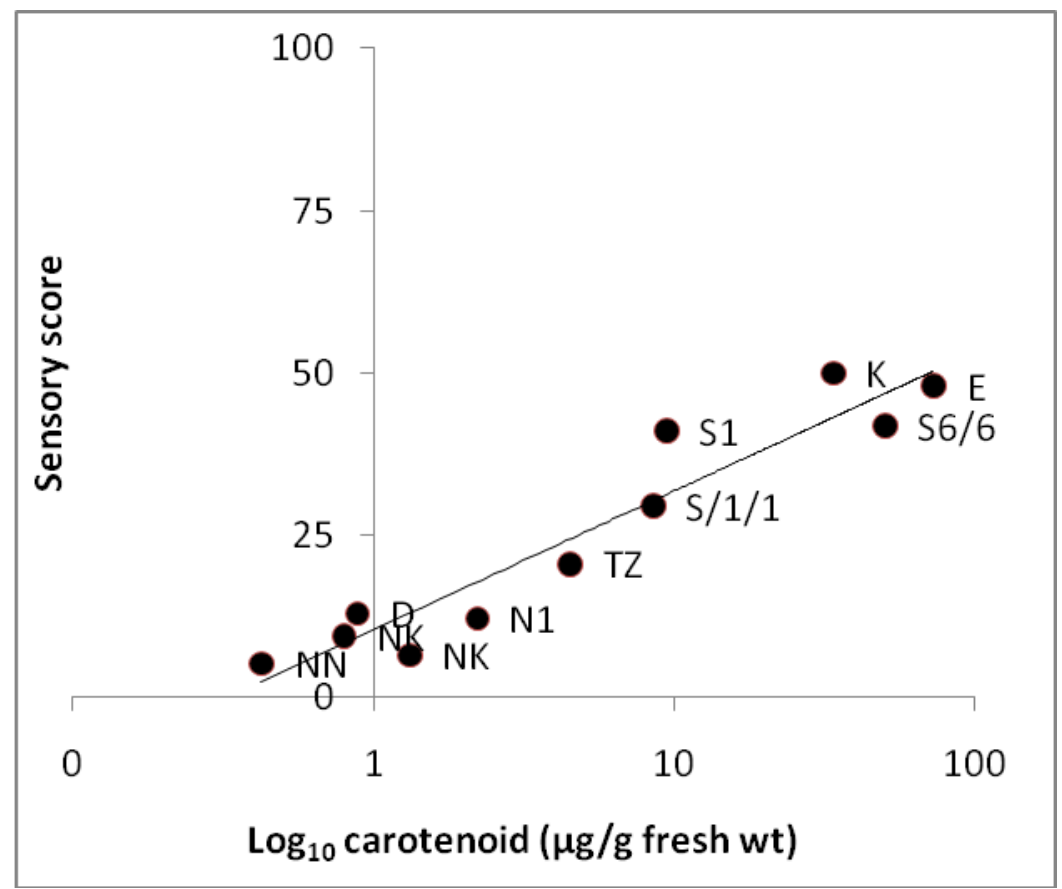

b) Pumpkin odour

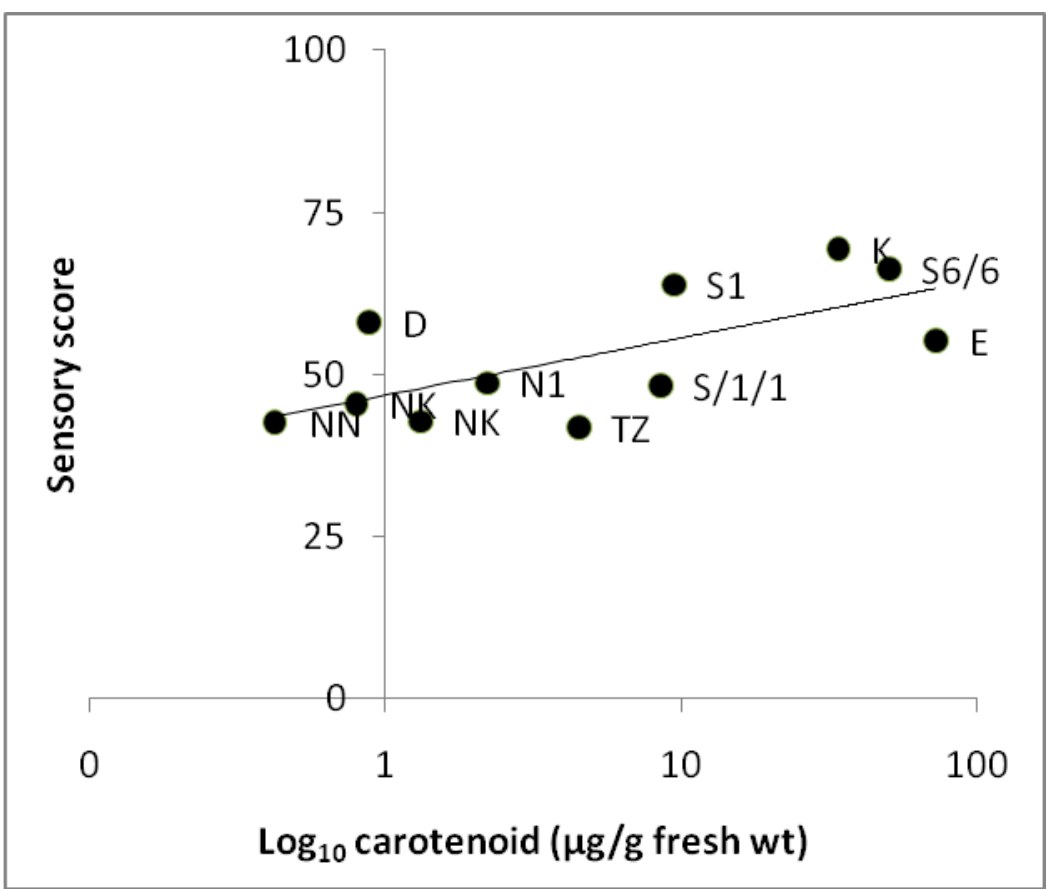


c) Smooth appearance

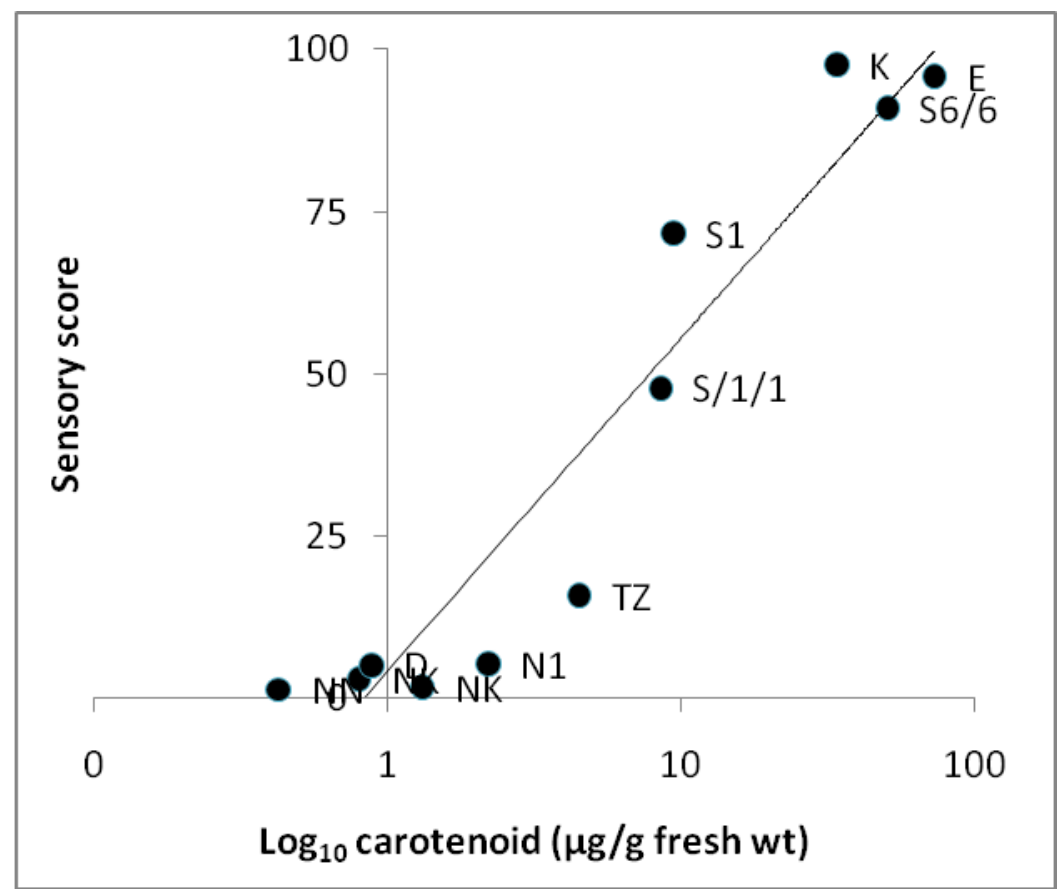

d) Orange colour 


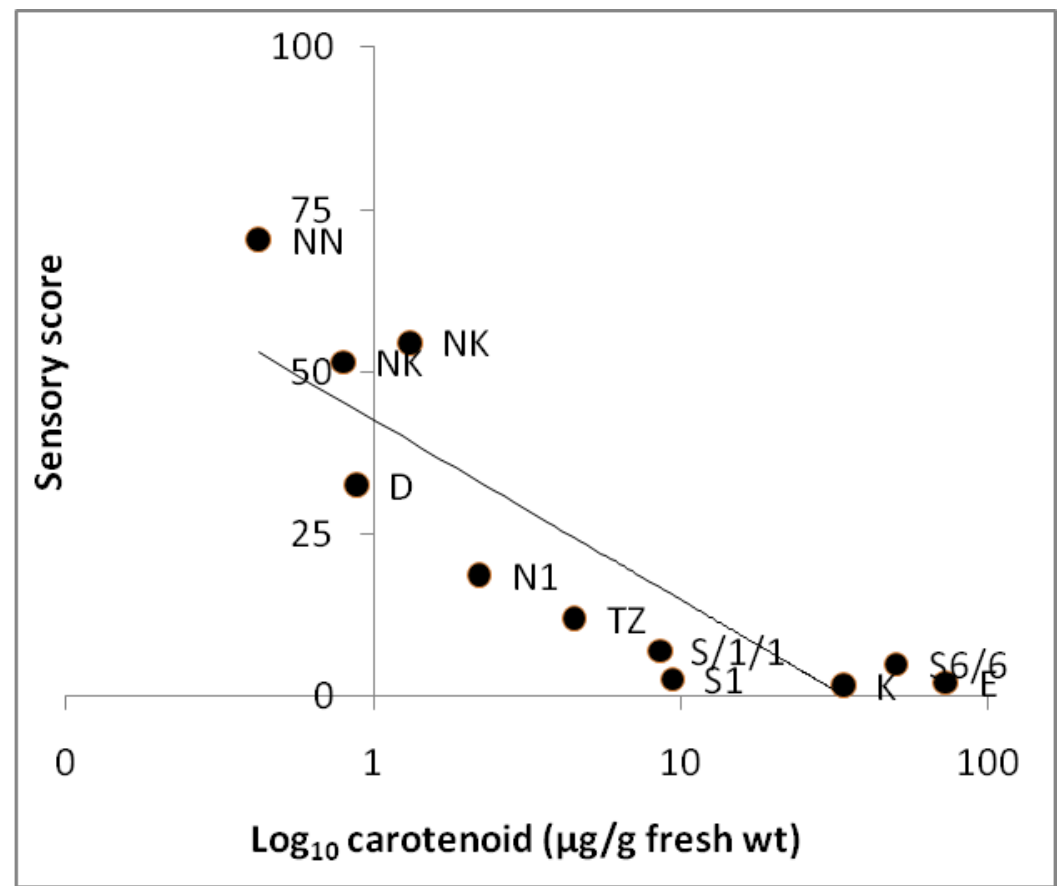

e) White colour

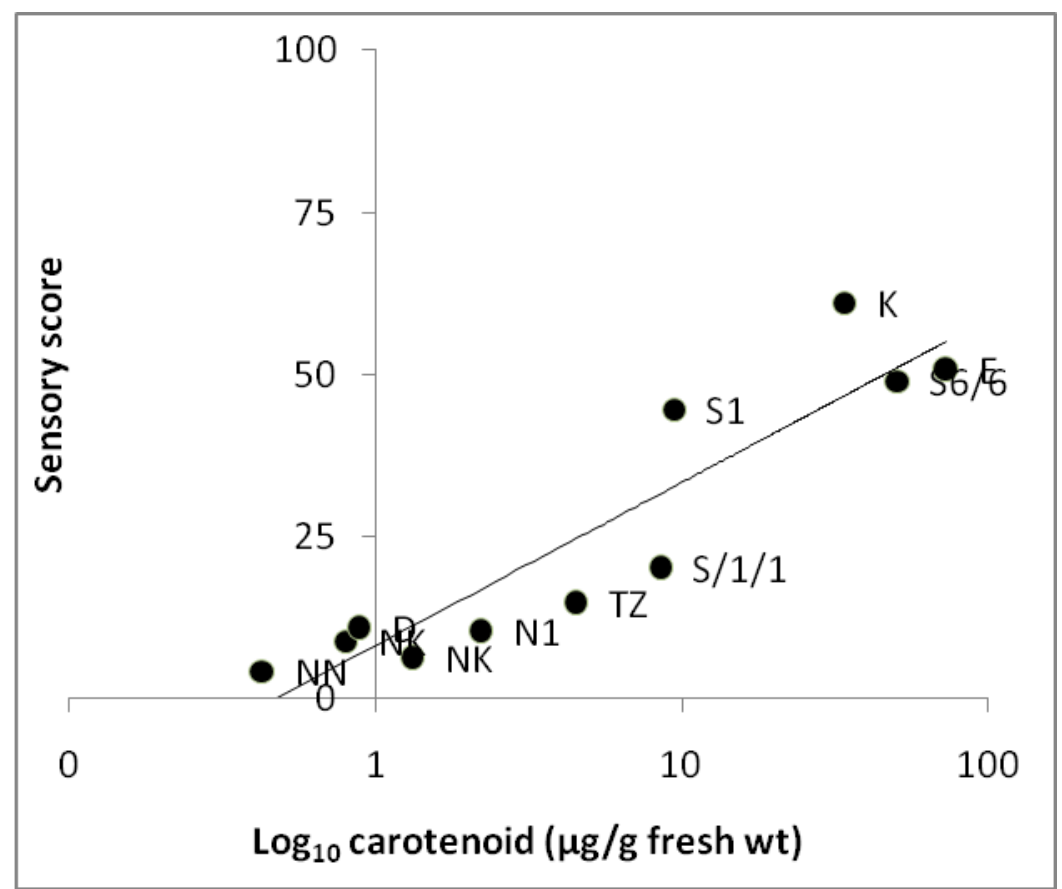


f) Pumpkin taste

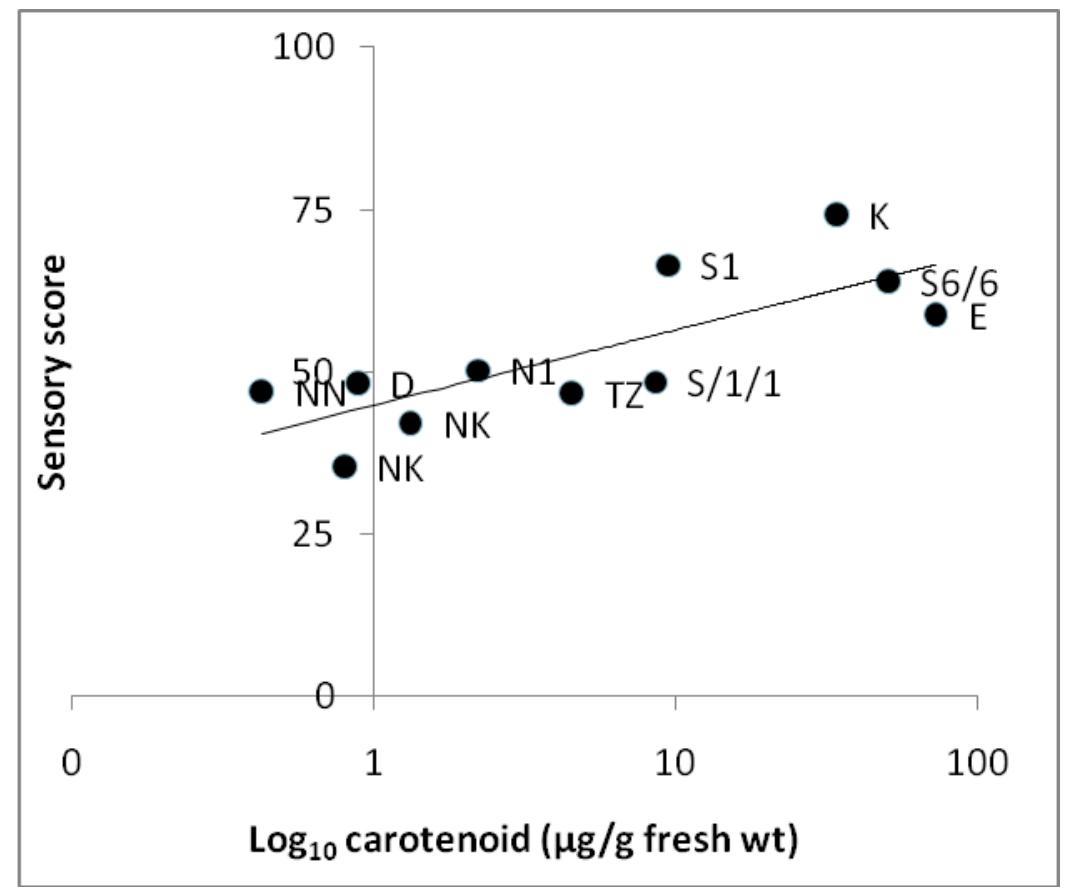

g) Soft texture

Where: $\mathrm{NN}=$ Ndikirya N'omwami, $\mathrm{NK}=$ Nakakande, $\mathrm{D}=$ Dimbuka, NK $=$ New Kawogo, N1 = Naspot $1, \mathrm{TZ}=$ Tanzania, $\mathrm{S} / 1 / 1=\mathrm{SPK} 004 / 1 / 1, \mathrm{~S} 1=\mathrm{SPK} 004 / 1, \mathrm{~K}=$ Kakamega, S6/6 = SPK004/6/6 and E = Ejumula. The mean values for sensory scores can be found in table 1 and the carotenoid contents in table 3.

Fig 3. Stepwise regression models for the relationship between sensory attributes and the Logarithm of total carotenoid content of sweet potato ( $\mu \mathrm{g} / \mathrm{g}$ fresh weight) 


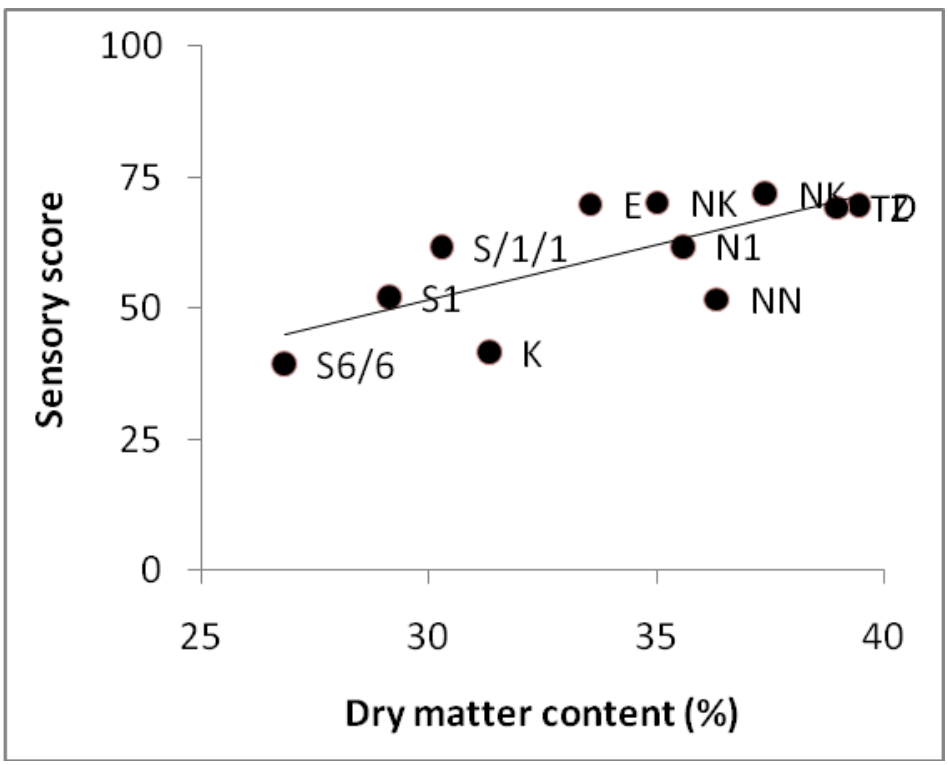

a) Sweet taste

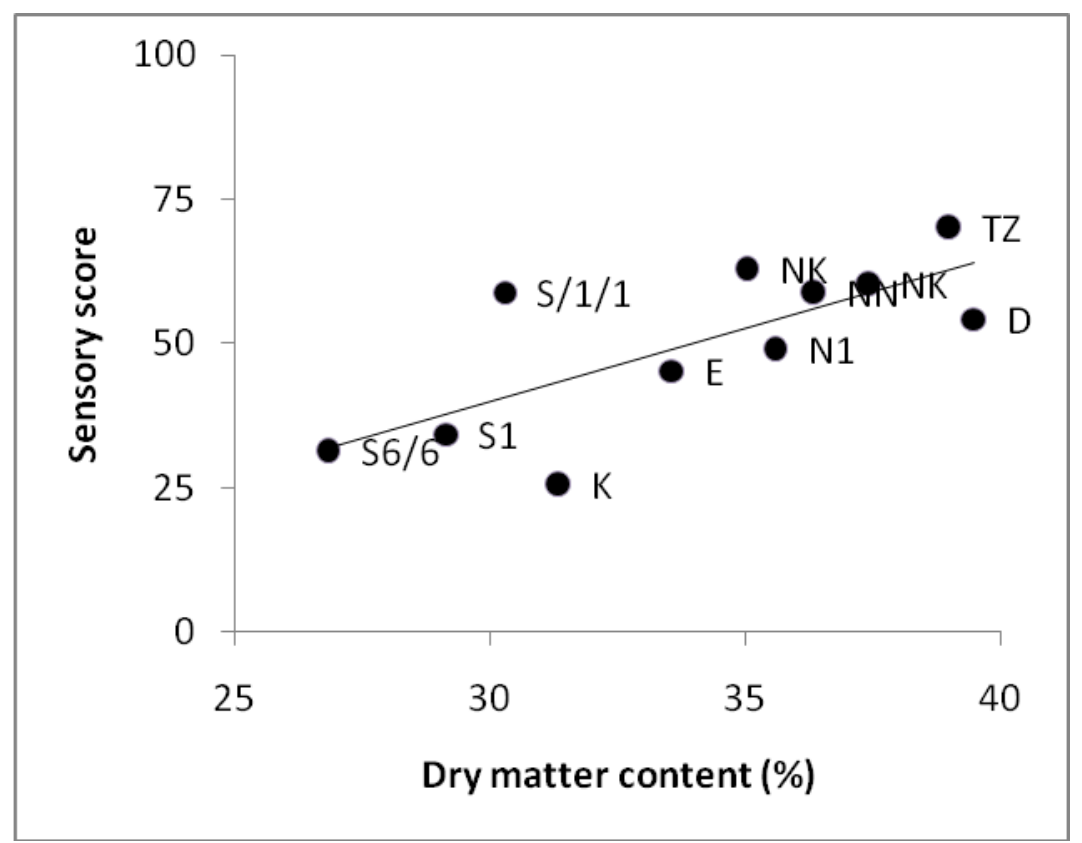

b) Crumbly texture (hand) 


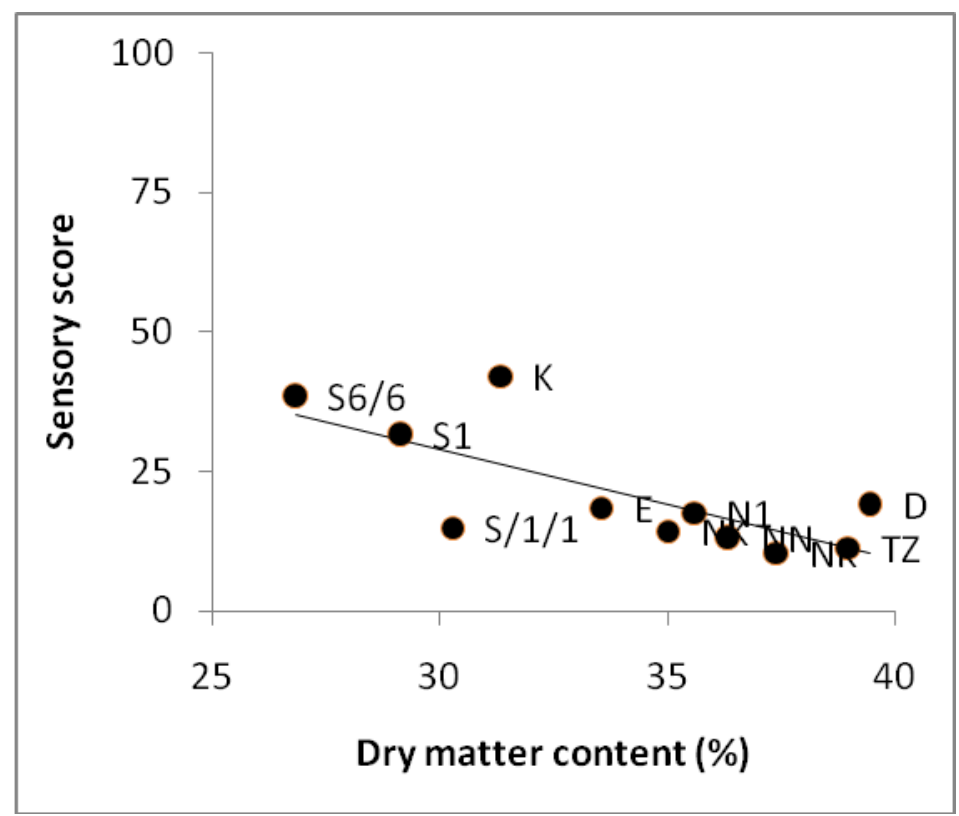

c) Watery texture

Where: $\mathrm{NN}=$ Ndikirya N'omwami, $\mathrm{NK}=$ Nakakande, $\mathrm{D}=$ Dimbuka, $\mathrm{NK}=$ New Kawogo, $\mathrm{N} 1=$ Naspot 1, TZ = Tanzania, S/1/1 = SPK004/1/1, S1 = SPK004/1, K = Kakamega, S6/6 = SPK004/6/6 and E = Ejumula. The mean values for the sensory scores can be found in table 1 and the dry matter contents in table 3.

Fig 4. Stepwise regression models for the relationship between sensory attributes and the dry matter content $(\%)$ of sweet potato 
Table 1

Mean scores for each of the sensory attributes by variety

\begin{tabular}{|c|c|c|c|c|c|c|c|c|c|c|c|c|c|c|c|c|c|c|c|c|c|c|c|c|}
\hline \multirow{2}{*}{$\begin{array}{l}\text { Variety } \\
\text { Nakakande }\end{array}$} & \multicolumn{4}{|c|}{ Sweet potato odour } & \multicolumn{4}{|c|}{ Pumpkin odour } & \multicolumn{4}{|c|}{ Smooth appearance } & \multicolumn{4}{|c|}{ Yellow colour } & \multicolumn{4}{|c|}{ Orange colour } & \multicolumn{4}{|c|}{ White colour } \\
\hline & 82.2 & d & \pm & 2.7 & 9.5 & a & \pm & 3.7 & 45.4 & $\mathrm{a}, \mathrm{b}, \mathrm{c}$, & \pm & 4.9 & 15.9 & a & \pm & 3.9 & 3.1 & $\mathrm{a}, \mathrm{b}$ & \pm & 1.1 & 51.5 & d & \pm & 5.0 \\
\hline $\mathrm{TZ}$ & 75.6 & d & \pm & 4.5 & 20.6 & $\mathrm{a}, \mathrm{b}$ & \pm & 5.6 & 41.9 & $\mathrm{a}$ & \pm & 5.3 & 70.0 & $\mathrm{c}$ & \pm & 4.7 & 15.9 & $\mathrm{~b}$ & \pm & 4.1 & 12.0 & $\mathrm{a}, \mathrm{b}$ & \pm & 2.0 \\
\hline Ndikirya N'omwami & 74.5 & $\mathrm{~d}$ & \pm & 4.2 & 5.3 & $\mathrm{a}$ & \pm & 1.7 & 42.6 & $\mathrm{a}$ & \pm & 5.8 & 3.6 & $\mathrm{a}$ & \pm & 1.1 & 1.4 & $\mathrm{a}$ & \pm & 0.5 & 70.4 & $\mathrm{e}$ & \pm & 5.1 \\
\hline New Kawogo & 73.0 & $\mathrm{~d}$ & \pm & 5.2 & 6.5 & $\mathrm{a}$ & \pm & 1.8 & 42.8 & $\mathrm{a}, \mathrm{b}$ & \pm & 5.2 & 12.7 & $\mathrm{a}$ & \pm & 4.2 & 1.7 & $\mathrm{a}$ & \pm & 0.5 & 54.5 & d & \pm & 5.2 \\
\hline SPK004/1/1 & 67.9 & $\mathrm{c}, \mathrm{d}$ & \pm & 3.9 & 29.5 & $\mathrm{~b}, \mathrm{c}$ & \pm & 6.0 & 48.3 & $\mathrm{a}, \mathrm{b}, \mathrm{c}, \mathrm{d}$ & \pm & 5.1 & 64.3 & $\mathrm{c}$ & \pm & 5.4 & 47.9 & $\mathrm{c}$ & \pm & 5.3 & 7.0 & $\mathrm{a}, \mathrm{b}$ & \pm & 1.7 \\
\hline Naspot 1 & 78.7 & d & \pm & 3.8 & 12.2 & $\mathrm{a}, \mathrm{b}$ & \pm & 3.4 & 48.7 & $\mathrm{a}, \mathrm{b}, \mathrm{c}, \mathrm{d}$ & \pm & 5.0 & 58.5 & $\mathrm{c}$ & \pm & 4.8 & 5.4 & $a, b$ & \pm & 1.5 & 18.8 & $\mathrm{~b}$ & \pm & 2.8 \\
\hline SPK004/1 & 51.2 & $\mathrm{~b}, \mathrm{c}$ & \pm & 5.6 & 41.1 & $\mathrm{c}, \mathrm{d}$ & \pm & 6.6 & 63.9 & $\mathrm{~b}, \mathrm{c}, \mathrm{d}, \mathrm{e}$ & \pm & 4.8 & 41.9 & $\mathrm{~b}$ & \pm & 4.8 & 71.7 & $\mathrm{~d}$ & \pm & 5.3 & 2.6 & $\mathrm{a}$ & \pm & 0.7 \\
\hline SPK004/6/6 & 43.0 & $\mathrm{a}, \mathrm{b}$ & \pm & 5.9 & 41.9 & $\mathrm{c}, \mathrm{d}$ & \pm & 6.4 & 66.3 & $\mathrm{c}, \mathrm{d}, \mathrm{e}$ & \pm & 5.0 & 9.2 & $\mathrm{a}$ & \pm & 2.5 & 90.9 & $\mathrm{e}$ & \pm & 5.0 & 5.0 & $\mathrm{a}, \mathrm{b}$ & \pm & 3.5 \\
\hline Kakamega & 39.0 & $\mathrm{a}, \mathrm{b}$ & \pm & 4.6 & 49.9 & $\mathrm{~d}$ & \pm & 7.0 & 69.4 & $\mathrm{~d}, \mathrm{e}$ & \pm & 4.9 & 14.1 & $\mathrm{a}$ & \pm & 3.1 & 97.7 & $\mathrm{e}$ & \pm & 1.4 & 1.8 & $\mathrm{a}$ & \pm & 0.6 \\
\hline Sig & & $<0$. & & & & $<0.0$ & & & & $<0.00$ & & & & $<0$. & & & & $<0$. & & & & $<0$. & & \\
\hline
\end{tabular}

Table 1 (continued)

\begin{tabular}{|c|c|c|c|c|c|c|c|c|c|c|c|c|c|c|c|c|c|c|c|c|c|c|c|c|c|c|c|c|}
\hline \multirow{2}{*}{$\frac{\text { Variety }}{\text { Nakakande }}$} & \multicolumn{4}{|c|}{ Uniform colour } & \multicolumn{4}{|c|}{ Sweet taste } & \multicolumn{4}{|c|}{ Pumpkin taste } & \multicolumn{4}{|c|}{ Crumbly texture } & \multicolumn{4}{|c|}{ Soft texture } & \multicolumn{4}{|c|}{ Fibrous texture } & \multicolumn{4}{|c|}{ Watery texture } \\
\hline & 42.3 & $\mathrm{a}$ & \pm & 4.8 & 72.0 & $\mathrm{e}$ & \pm & 3.7 & 8.8 & $\mathrm{a}$ & \pm & 3.0 & 60.3 & $\mathrm{e}, \mathrm{f}$ & \pm & 5.1 & 35.4 & $\mathrm{a}$ & \pm & 4.9 & 20.0 & $\mathrm{a}$ & \pm & & 10.3 & $\mathrm{a}$ & \pm & 3.1 \\
\hline $\mathrm{TZ}$ & 41.6 & a & \pm & 4.4 & 69.2 & $\mathrm{~d}, \mathrm{e}$ & \pm & 4.1 & 14.8 & $\mathrm{a}$ & \pm & 4.8 & 70.2 & $\mathrm{f}$ & \pm & 5.4 & 46.7 & $\mathrm{a}, \mathrm{b}, \mathrm{c}$ & \pm & 5.7 & 17.5 & $\mathrm{a}$ & \pm & 4.3 & 11.2 & a & \pm & 2.9 \\
\hline Ndikirya N'omwami & 65.2 & $\mathrm{~b}, \mathrm{c}, \mathrm{d}$ & \pm & 4.4 & 51.7 & $\mathrm{~b}, \mathrm{c}$ & \pm & 4.9 & 4.2 & a & \pm & 1.4 & 58.9 & $\mathrm{e}, \mathrm{f}$ & \pm & 6.4 & 47.0 & $\mathrm{a}, \mathrm{b}, \mathrm{c}$ & \pm & 5.4 & 15.0 & $\mathrm{a}$ & \pm & 3.5 & 13.1 & a & \pm & 2.5 \\
\hline New Kawogo & 44.9 & $a, b$ & \pm & 4.6 & 70.2 & $\mathrm{e}$ & \pm & 4.4 & 6.4 & $\mathrm{a}$ & \pm & 1.6 & 63.0 & $\mathrm{e}, \mathrm{f}$ & \pm & 5.8 & 42.2 & $\mathrm{a}, \mathrm{b}$ & \pm & 4.8 & 21.4 & $\mathrm{a}$ & \pm & 4.5 & 14.2 & a & \pm & 3.0 \\
\hline SPK004/1/1 & 43.9 & $\mathrm{a}$ & \pm & 4.2 & 61.7 & $\mathrm{c}, \mathrm{d}, \mathrm{e}$ & \pm & 4.2 & 20.3 & $\mathrm{a}$ & \pm & 4.8 & 58.8 & $\mathrm{e}, \mathrm{f}$ & \pm & 5.8 & 48.5 & $a, b, c$ & \pm & 4.9 & 19.6 & $\mathrm{a}$ & \pm & 4.1 & 14.9 & $\mathrm{a}$ & \pm & 3.7 \\
\hline Naspot 1 & 46.9 & $a, b$ & \pm & 4.3 & 61.8 & $\mathrm{c}, \mathrm{d}, \mathrm{e}$ & \pm & 3.9 & 10.5 & a & \pm & 3.4 & 49.1 & $\mathrm{c}, \mathrm{d}, \mathrm{e}, \mathrm{f}$ & \pm & 5.3 & 50.3 & $\mathrm{a}, \mathrm{b}, \mathrm{c}, \mathrm{d}$ & \pm & 4.9 & 16.0 & $\mathrm{a}$ & \pm & 3.7 & 17.5 & $\mathrm{a}, \mathrm{b}$ & \pm & 3.5 \\
\hline Ejumula & 55.4 & $\mathrm{a}, \mathrm{b}, \mathrm{c}$ & \pm & 5.7 & 69.9 & $\mathrm{e}$ & \pm & 4.5 & 50.9 & $\mathrm{~b}, \mathrm{c}$ & \pm & 7.1 & 45.2 & $\mathrm{~b}, \mathrm{c}, \mathrm{d}, \mathrm{e}$ & \pm & 6.2 & 58.9 & $\mathrm{~b}, \mathrm{c}, \mathrm{d}, \mathrm{e}$ & \pm & 7.0 & 17.5 & $\mathrm{a}$ & \pm & 4.6 & 18.4 & $a, b$ & \pm & 4.3 \\
\hline Dimbuka & 64.7 & $\mathrm{~b}, \mathrm{c}, \mathrm{d}$ & \pm & 3.9 & 69.8 & $\mathrm{e}$ & \pm & 3.0 & 11.1 & a & \pm & 3.5 & 54.1 & $\mathrm{~d}, \mathrm{e}, \mathrm{f}$ & \pm & 6.2 & 48.3 & $a, b, c$ & \pm & 5.9 & 17.5 & $\mathrm{a}$ & \pm & 4.5 & 19.2 & $a, b$ & \pm & 4.4 \\
\hline SPK004/1 & 54.6 & $\mathrm{a}, \mathrm{b}, \mathrm{c}$ & \pm & 5.3 & 52.3 & $\mathrm{~b}, \mathrm{c}, \mathrm{d}$ & \pm & 4.5 & 44.6 & $\mathrm{~b}, \mathrm{c}$ & \pm & 6.6 & 34.2 & $\mathrm{a}, \mathrm{b}, \mathrm{c}, \mathrm{d}$ & \pm & 5.1 & 66.5 & $\mathrm{c}, \mathrm{d}, \mathrm{e}$ & \pm & 4.9 & 22.8 & $\mathrm{a}$ & \pm & 5.2 & 31.8 & $\mathrm{~b}, \mathrm{c}$ & \pm & 5.1 \\
\hline SPK004/6/6 & 52.1 & $\mathrm{a}, \mathrm{b}, \mathrm{c}$ & \pm & 5.5 & 39.4 & $\mathrm{a}, \mathrm{b}$ & \pm & 4.6 & 49.0 & $\mathrm{~b}, \mathrm{c}$ & \pm & 6.5 & 31.5 & $\mathrm{a}, \mathrm{b}, \mathrm{c}$ & \pm & 5.4 & 64.0 & $\mathrm{c}, \mathrm{d}, \mathrm{e}$ & \pm & 5.8 & 13.3 & $\mathrm{a}$ & \pm & 3.2 & 38.5 & $\mathrm{~d}$ & \pm & 5.7 \\
\hline Kakamega & 68.3 & $\mathrm{c}, \mathrm{d}$ & \pm & 5.6 & 41.6 & $\mathrm{a}, \mathrm{b}$ & \pm & 4.8 & 61.0 & $\mathrm{c}$ & \pm & 6.5 & 25.6 & $a, b$ & \pm & 5.2 & 74.2 & $\mathrm{e}$ & \pm & 4.1 & 11.4 & $\mathrm{a}$ & \pm & 2.8 & 42.0 & $\mathrm{~d}$ & \pm & 6.2 \\
\hline Sig & & $<0.0$ & & & & $<0.0$ & & & & $<0$. & & & & $<0.00$ & & & & $<0.00$ & & & & 0.3 & & & & $<0.0$ & & \\
\hline
\end{tabular}

Where: letters after each mean value indicate significant differences according the Tukey test; plus or minus values indicate the

standard error of the mean 
Table 2

Probability values for variety and panellist interactions (mixed effect model)

\begin{tabular}{lc} 
Sensory attribute & Variety + Panellist interaction (Chi square) \\
\hline Sweet potato odour & 0.802 \\
Pumpkin odour & $<0.001$ \\
Smooth appearance & 1.000 \\
Yellow colour & 0.573 \\
Orange colour & 0.313 \\
White colour & 0.183 \\
Uniform colour & 1.000 \\
Sweet taste & 1.000 \\
Pumpkin taste & 0.001 \\
Crumbly texture & 0.999 \\
Soft texture & 1.000 \\
Fibrous texture & 1.000 \\
Watery texture & 0.442
\end{tabular}


Table 3

Mean total carotenoid ( $\mu \mathrm{g} / \mathrm{g}$ fresh weight and $\mu \mathrm{g} / \mathrm{g}$ dry weight ) and dry matter $(\%)$ contents of sweet potato varieties tested by the sensory panel

Total carotenoid Content

\begin{tabular}{|c|c|c|c|c|c|c|}
\hline Sweet potato variety & $\mu \mathrm{g} / \mathrm{g}$ fres & h weight & $\mu \mathrm{g} / \mathrm{g}$ dry & weight & Dry matter & content (\%) \\
\hline Ejumula & $72.5 \pm$ & 0.519 & $216.0 \pm$ & 1.546 & $33.5 \pm$ & 0.003 \\
\hline SPK004/6/6 & $50.2 \pm$ & 1.059 & $187.2 \pm$ & 3.951 & $26.8 \pm$ & 0.001 \\
\hline Kakamega & $33.9 \pm$ & 1.501 & $108.2 \pm$ & 4.791 & $31.3 \pm$ & 0.005 \\
\hline SPK004/1 & $9.4 \pm$ & 0.156 & $32.4 \pm$ & 0.534 & $29.1 \pm$ & 0.002 \\
\hline SPK004/1/1 & $8.5 \pm$ & 0.612 & $28.2 \pm$ & 2.030 & $30.3 \pm$ & 0.003 \\
\hline Tanzania & $4.5 \pm$ & 0.114 & $11.5 \pm$ & 0.291 & $38.9 \pm$ & 0.003 \\
\hline Naspot 1 & $2.2 \pm$ & 0.119 & $6.2 \pm$ & 0.335 & $35.6 \pm$ & 0.001 \\
\hline New Kawogo & $1.3 \pm$ & 0.051 & $3.8 \pm$ & 0.149 & $35.0 \pm$ & 0.001 \\
\hline Dimbuka & $0.9 \pm$ & 0.042 & $2.2 \pm$ & 0.103 & $39.4 \pm$ & 0.064 \\
\hline Nakakande & $0.8 \pm$ & 0.035 & $2.1 \pm$ & 0.091 & $37.4 \pm$ & 0.001 \\
\hline
\end{tabular}

$\begin{array}{lllll}\text { Ndikilyanomwami } & 0.4 \pm & 0.005 & 1.2 \pm 0.015 & 36.3 \pm 0.002\end{array}$

Where values given are \pm the standard error of the mean $(n=3)$ 
Table 4

Total carotenoid ( $\mu \mathrm{g} / \mathrm{g}$ dry weight $)$, trans- $\beta$ and dry matter $(\%)$ contents of sweet potato varieties previously elsewhere

\begin{tabular}{|c|c|c|c|c|c|c|}
\hline \multirow{3}{*}{$\begin{array}{l}\text { Variety } \\
\text { Ejumula }\end{array}$} & \multicolumn{3}{|c|}{ Carotenoid content $\left(\mu \mathrm{g} / \mathrm{g}^{*}\right)$ dry weight basis } & & & \\
\hline & \multicolumn{2}{|c|}{ trans- $\beta$-carotene } & \multirow{2}{*}{$\begin{array}{c}\text { total carotenoid } \\
250.6-300.5 \mathrm{c}\end{array}$} & \multicolumn{3}{|c|}{ Dry matter content (\%) } \\
\hline & $125 \mathrm{a}$ & $\begin{array}{c}185.6-324.8 \\
b\end{array}$ & & $31.4 a$ & $34.6 b$ & $30.9-31.5 \mathrm{c}$ \\
\hline SPK004/6/6 & - & $\begin{array}{c}97.9-363.8 \\
b\end{array}$ & $168.1-172.9 \mathrm{c}$ & - & $30.3 b$ & $22.8-28.8 c$ \\
\hline $\begin{array}{l}\text { Kakamega } \\
\text { (SPK004) }\end{array}$ & $20-68$ a & $\begin{array}{c}48.2-191.7 \\
b\end{array}$ & $75.2-107.9$ c & $36.5 a$ & $35.0 \mathrm{~b}$ & $32.2-38.1 \mathrm{c}$ \\
\hline SPK004/1 & - & $\begin{array}{c}44.3-192.7 \\
b\end{array}$ & $47.9-96.1 \mathrm{c}$ & - & $34.6 b$ & $31.7-32.9 c$ \\
\hline SPK004/1/1 & - & $\begin{array}{c}85.6-219.3 \\
b\end{array}$ & $41.7-78.5 c$ & - & $33.5 b$ & $30.3-33.1 c$ \\
\hline Tanzania & - & - & - & - & - & - \\
\hline Naspot 1 & $2-4 a$ & - & - & $35.9-39.3 a$ & - & - \\
\hline Dimbuka & $2 \mathrm{a}$ & - & - & $32.3 a$ & - & - \\
\hline Nakakande & - & - & - & - & - & - \\
\hline New Kawogo & $\begin{array}{c}0.4-0.6 \\
a\end{array}$ & - & - & $39.9 a$ & - & - \\
\hline $\begin{array}{l}\text { Ndikiry } \\
\text { N'omwami }\end{array}$ & - & - & - & - & - & - \\
\hline
\end{tabular}

Where $\mathrm{a}=$ Namutebi et al., 2004, b = Bengsston et al. 2008 and $\mathrm{c}=$ Bechoff et al., 2010 
Table 5

Correlation between the $\log _{10}$ carotenoid content (fresh weight basis), dry matter content and sensory attributes of sweet potato

Dry matter content Log10 total carotenoid

$(\%) \quad(\mu \mathrm{g} / \mathrm{g}$ fresh weight $)$

Sweet potato odour

$.760^{* *}-.902^{* *}$

Pumpkin odour

$-.721^{*}$

$.952^{* *}$

Smooth appearance

$-.645^{*}$

$.673^{*}$

Yellow colour

.169

$-.075$

Orange colour

$-.780^{* *}$

$.951^{* *}$

White colour

.569

$-.865^{* *}$

Uniform colour (cut surface)

$-.070$

.090

Sweet taste

$.725^{*}$

$-.446$

Pumpkin taste

$-.717^{*}$

$.917^{* *}$

Crumbly texture (hand)

$.731^{*}$

$-.681^{*}$

Watery texture

$-.728^{*}$

$.667^{*}$

Where $^{*}=$ significant at $<0.05$ and $* *=$ significant at $<0.001 ; n=11$ 